\title{
Multisegmental lateral pilar leiomyoma: An atypical
}

\section{case}

\section{Meryem Soughi, Fatiha Litam}

\author{
Dermatology Department, Taounat Peripheral Hospital, Taounat, Morocco \\ Corresponding author: Meryem Soughi, MD, E-mail: msoughi@gmail.com
}

Pilar leiomyoma is a benign smooth muscle tumor arising from the arrector pili muscle, it is representing 3 to $5 \%$ of leiomyoma lesions [1]. Segmental distribution of pilar leiomyoma is common. However, multisegmental distribution is rare [2]. We report an exceptional case presenting unilateral and multisegmental localization in a young man. The treatment can be difficult whene it's a multiple and painful. Various pharmacological options might include nifedipine, doxazocine, gabapentine, and Topical 9\% hyoscine hydrobromide have been used to relieve the pain associated with these tumors [2].

Our case was 24-year-old man. Along 3 years, he presented a multiple pink papules and nodules. Some lesions were slightly pigmented and localized at the level of the right half of the thorax (Fig. 1) and the posterior and anterior of the homolateral arm (Fig. 2). The patient reported intense pain especially during the

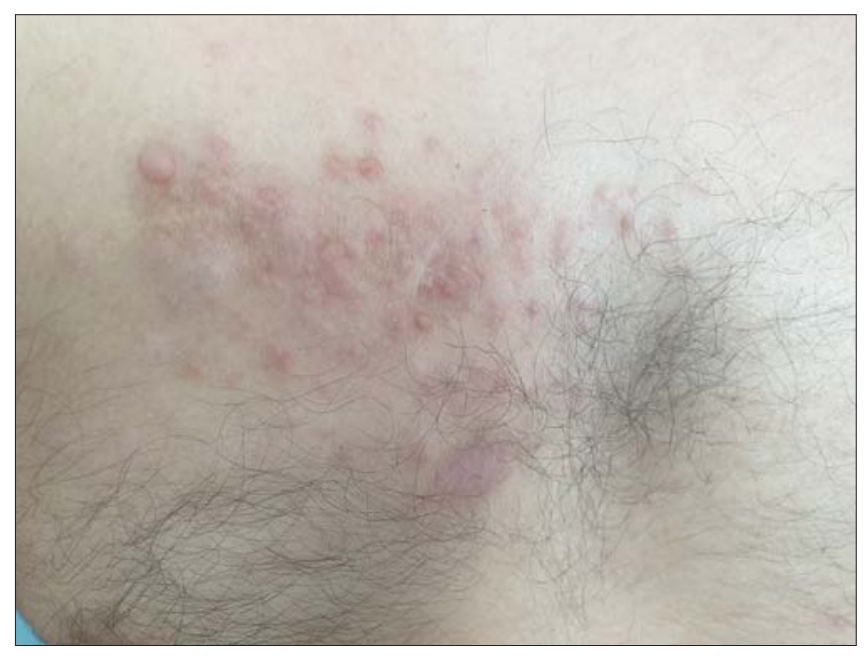

Figure 1: Pink papules and nodules level of the right half of the thorax. cold weather stages. The dermoscopy did not show any specific signs except generalized hypopigmentation with a pale and pink appearance in some lesions (Figure 3). The histology confirmed a pilar leiomyoma.

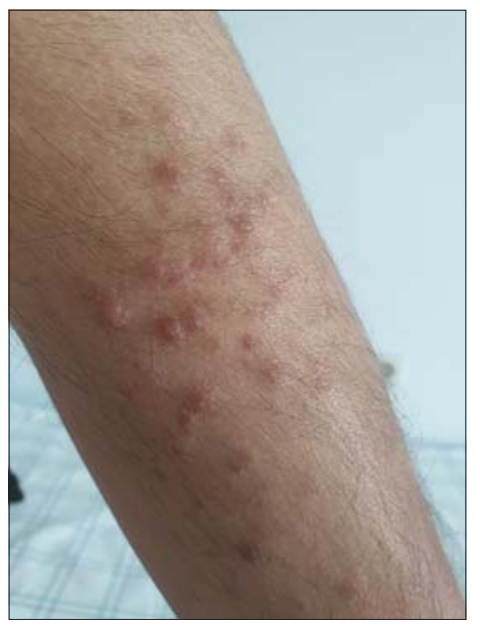

Figure 2: Pigmented papules and nodules of the posterior of arm.

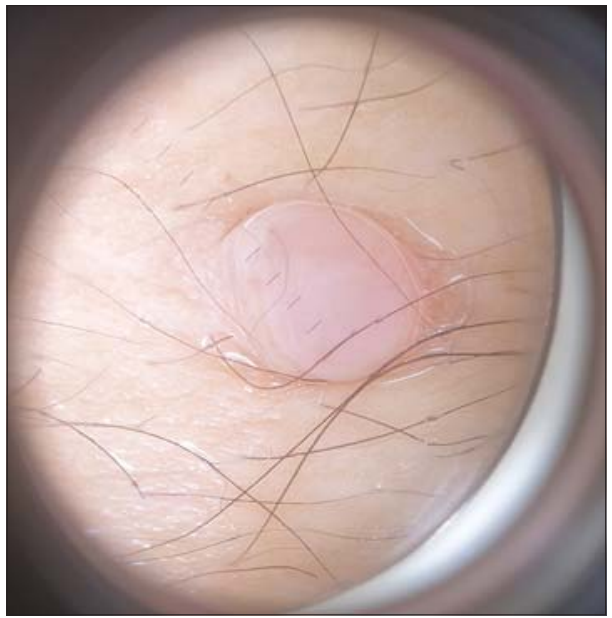

Figure 3: Dermoscopy show hypopigmentation with a pale and pink appearance in the lesion. 
The renal ultrasound was unremarkable and the patient was treated by Nifedipine to relieve pain.

\section{CONSENT}

The examination of the patient was conducted according to the principles of the Declaration of Helsinki.

The authors certify that they have obtained all appropriate patient consent forms, in which the patients gave their consent for images and other clinical information to be included in the journal. The patients understand that their names and initials will not be published and due effort will be made to conceal their identity, but that anonymity cannot be guaranteed.

\section{REFERENCES}

1. Hoyt BS, Tschen JA, Cohen PR. Solitary pilar leiomyoma of the nasal dorsum: case report and literature review. Indian J Dermatol. 2015;1:82-4.

2. Kudligi C, Khaitan BK, Bhagwat PV, Asati DP. Unilateral multisegmental leiomyomas: A report of rare case. Indian J Dermatol. 2013;58:160

Copyright by Meryem Soughi, et al. This is an open-access article distributed under the terms of the Creative Commons Attribution License, which permits unrestricted use, distribution, and reproduction in any medium, provided the original author and source are credited.

Source of Support: Nil, Conflict of Interest: None declared. 